\title{
Employment and rebellion in conflicted and fragile
}

\section{states}

\section{Jobs programs may not reduce rebellion}

Keywords: civil war, peacebuilding, fragile states, unemployment, violence

\section{ELEVATOR PITCH}

In addition to the heart-breaking human costs, violent civil rebellion is a cause of chronic economic underdevelopment. Employment programs with former combatants and at-risk youth have improved their livelihoods, but not their support for non-violence and respect for law. Rebel groups provide security and social benefits that formal employment does not offer, possibly making switching out of rebellion into formal employment unappealing. However, a jobs program that addressed the psycho-social motivations to join rebel groups resulted in significant reductions in crime and violence. This is an important step forward in our understanding of how to lure people away from violent rebellion.

\section{KEY FINDINGS}

\section{Pros}

๑ The economic idea of "opportunity cost" suggests that rebels should be willing to switch out of rebellion as soon as sufficiently lucrative and formal employment opportunities become available.

$\oplus$ Civil violence can increase following negative economic shocks, as the resulting unemployment releases a pool of labor for rebel groups.

๑ Unemployment may create an aggrieved underclass susceptible to rebel recruitment.

( People who have steady jobs may become more responsible, less violent, more respectful of authority, and invest more in their communities.
In Iraq, significant violent acts decrease when unemployment rates rise

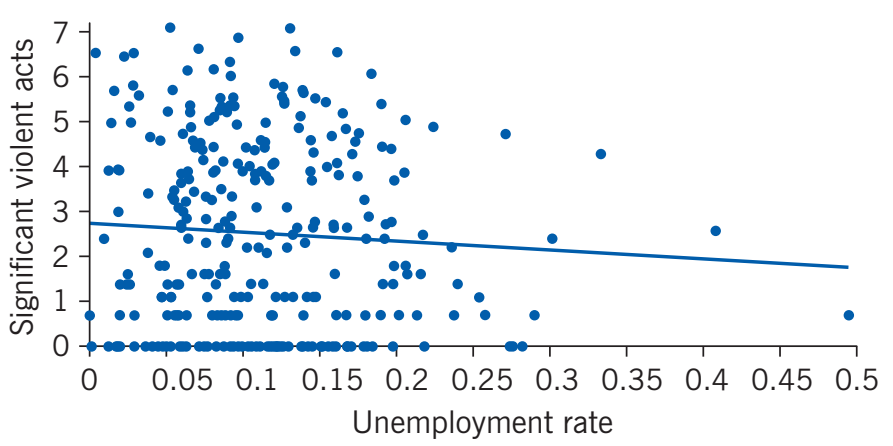

Note: A ten-percentage point increase in unemployment is correlated with almost a $20 \%$ decrease in violent acts (measured in logarithm).

Source: Data from [1]; 2004-2007.

\section{Cons}

- Rebel groups may offer personal security for people in fragile states that is not otherwise available through formal employment.

- Participation in rebellion offers a number of social benefits, such as a sense of contributing to an important just cause, that are not offered through formal employment opportunities.

- Studies have failed to provide a clear causal link between unemployment and civil war violence.

- Improving ex-combatants' and at-risk youths' livelihoods does not make their political and social views less violent or more respectful of legal authority.

\section{AUTHOR'S MAIN MESSAGE}

Aid agencies use jobs programs to try to lure people away from rebel activity. But there is no established empirical link between employment and rebel activity at the macro level, or support for non-violence and legitimate authority at the micro level. Evidence indicates that social motivations (e.g. a perceived "just cause") are important reasons for participating in rebel organizations, and that the behaviour of "at-risk" youths can be significantly changed with psychological and social therapies that break the bad habits and indoctrination that influence decisions to join rebel groups. Civil violence is not only, or predominantly, an economic problem, but also a psychological, social, and political one that should be approached holistically, rather than addressed simply by creating jobs programs. 


\section{MOTIVATION}

As well as the tragic human costs involved, civil war also destroys scarce capital resources, lures vulnerable individuals into destructive rather than productive pursuits, and disrupts the political and social stability necessary for economic development [2]. Approximately two billion people currently live in conflicted and fragile states-i.e. low-income countries (LICs) that are characterized by weak state capacity and/or are conflict-afflicted. Estimates suggest that by 2030 all of the remaining countries currently classified as LICs will be conflicted and fragile [3]. Many aid programs in these states are motivated by the theory that increasing formal employment opportunities will lure the perpetrators of civil violence away from rebel groups [1]. However, the evidence for this is scant. Social incentives, people's fear for their personal safety, and the nature of labor markets in LICs, can help explain this weak link, and call into question the efficacy of jobs programs alone in reducing rebellion and lawlessness in these countries. In contrast, programs that address the psycho-social reasons for participating in these groups, such as the need to contribute to an important cause greater than oneself, and for being vulnerable to the indoctrination of these movements, have shown promise in field trials and have resulted in large and sustained reductions in crime and violence.

\section{DISCUSSION OF PROS AND CONS}

\section{Distinguishing crime from rebellion}

In discussing the effect of employment on rebellion and more general lawlessness, it is important to first distinguish between criminals and rebels. One significant difference between these groups is that while rebels are more generally motivated by social causes, criminals are motived by material gain. The extent to which this statement is accurate varies from case to case, of course, but it is fair to say that most rebels do not think of themselves as criminals. As such, a possible shortcoming of well-known economic theories of rebellion is that they conflate these two distinct activities-i.e. criminal as opposed to rebellious behavior [4].

In contrast to economic theory, canonical counterinsurgency theory is based on the observation that insurgencies and rebellions, unlike crime, are motivated by a cause other than personal material enrichment. Indeed, one particular study goes as far as to say that if the cause is removed, an insurgency will collapse [5]. Another important difference between rebellion and crime is that many rebel movements receive voluntary material support (e.g. money, food, shelter) from the local population of the areas in which they operate. This is not universally true of all rebel movements, and some well-known rebel movements have been extremely abusive of the populations among which they operate, but it is certainly more likely to be true for rebel movements than for criminal enterprises.

Nevertheless, rebellion and crime are linked in at least two important ways. First, even rebel groups that are materially well-supported voluntarily by the local population will sometimes engage in illegal activities, such as robbery, to raise more funds. Thus an insurgency may lead to an increase in crime. Second, and more importantly for the purposes of this contribution, one prominent "cure" for rebellion used by the international humanitarian community-i.e. both non-governmental and inter-governmental organizations-is the same "cure" used for crime, namely, employment programs designed to lure "at-risk" youth away from rebel and criminal organizations and into formal employment. This suggests that the designers of international humanitarian programs believe that crime 
and rebellion are, at least in part, caused by much the same underlying problem, i.e. a lack of employment opportunities for at-risk youth, who then turn to crime and rebellion in order to improve their livelihoods and perhaps to change the political and economic system that has failed to address their needs. The extent to which this is true has yet to be proved empirically.

\section{Employment and rebellion}

There are several reasons for why we might expect to see a negative relationship between employment and rebellion, two of which can be characterized under the well-known categories of "greed" and "grievance" [6]. Under the greed hypothesis, rebels make money by looting and taxing local populations. Rebels are essentially criminals in this model and rebellion is a remunerative activity, much like any other job. Rebels compare the expected personal benefits of rebelling with the expected costs of participating in that "career," which include "opportunity costs," i.e. the costs associated with other employment opportunities that they may have foregone. If the expected net payoff is higher for rebellion than for taking up traditional employment, then the individual might choose a career as a rebel [4]. Although the authors of one study on this subject do not explicitly draw out the policy implications of their argument [6], it could be inferred that rebellion would therefore decrease as formal employment opportunities become more abundant-in which case jobs programs for at-risk youth should be an effective way to reduce rebellion and lawlessness.

A second possible link between employment, or more specifically unemployment, and rebellion falls under the "grievance" hypothesis. A large, unemployed underclass, especially if it is predominantly composed of disaffected youths or oppressed minorities, can provide a fertile breeding ground for rebels who wish to overthrow the status quo and to right perceived wrongs in society.

A third, and a more social argument, is that holding gainful employment may change people's preferences to be less violent and more respectful of legal authority. People who hold steady jobs may become more responsible, more invested, and more integrated in their communities. This micro-level social transformation might reduce individual impulses to engage in violence and thereby reduce the pool of socially disaffected people who are susceptible to rebel appeals.

However, empirical support for a positive link between unemployment and rebellion is weak. Some early suggested evidence in favor of a positive relationship between civil war violence and unemployment is that negative economic shocks, such as rainfall shortages or exogenous price reductions for important commodities, lead to a marked increase in civil war outbreak and violence. One interpretation of this finding is that these negative shocks cause unemployment, which releases a pool of labor that becomes available for criminal or rebel enterprises. The problem with this interpretation is that the evidence is too far removed from the employment-rebellion link to be taken as strong evidence for such a link. There are equally plausible rival explanations. For example, negative economic shocks also reduce state capacity through a reduction in the tax base, thereby making rebellion more tempting to would-be rebels, due to a higher probability of the rebellion's success against a weakened state.

When actual employment figures rather than economic shocks are considered, the hypothesized relationship between employment and rebellion largely disappears. Looking 
at a sample of significant violent events from insurgencies in Afghanistan, Iraq, and the Philippines, one study emphatically rejects what the authors call the "opportunity-cost model" (i.e. the theory that foregone opportunities of employment are taken into account by rebels). This model predicts that, regardless of an individual's motivation for joining rebel groups, potential increases through gainful employment, which would have to be foregone (or at least reduced) in order to participate in rebellion, raise the personal and financial cost of participating in rebellion. That being so, increases in employment opportunities should reduce the number of people who are willing to join an insurgency and therefore reduce insurgent activities [1]. However, one study actually finds a negative relationship between unemployment and violent acts in the three rebellions they study [1]. Another study finds a similar negative relationship between unemployment and terrorist attacks in Palestine [7].

\section{The causal relationship between violence and unemployment}

While it is not possible to discern from the studies referred to above what the direction of causality is that runs between violent acts and unemployment in the conflicts they study, the authors of one of the studies list several possible casual connections [1]. They suggest that increased employment may lead to increased incomes for more people and therefore to more predatory activity by criminals and rebels. It may also increase the price of information that counterinsurgent forces need to thwart insurgent attacks: as incomes are bolstered by more steady employment, locals may raise the price they charge for this information. Alternatively, efforts that successfully suppress violence, such as roadblocks and curfews, may also suppress employment, as people become more restricted in their movement. Finally, government strategy may increase both employment and violence, e.g. the state might increase public investment as well as step up attacks in selected areas as part of a counterinsurgency strategy.

Although these proposed causal suggestions are quite difficult to substantiate, the study raises an extremely important shortcoming of any strategy that proposes to use employment to combat rebellion: i.e. activities that the security forces must take to secure the population (e.g. road blocks, curfews, etc.) may actually work at cross-purposes with a strategy to increase employment. Conversely, however, successfully increasing employment may make it harder for security services to combat insurgency.

Such causal identification issues make experimental and quasi-experimental studies with ex-combatant and at-risk populations all the more important. Several such studies offer valuable insights in this regard. The first studied a program that was part of the World Bank's massive Multi-Country Demobilization and Reintegration Program, which was implemented throughout the Great Lakes region of Africa [8]. Specifically, the study looked at a program in Burundi in 2007 after the conclusion of the civil war in that country, that offered start-up capital, or job training to former rebels. Almost all of the beneficiaries took the start-up capital option, which is a common theme across such programs [3]. An unintended bureaucratic problem in the implementation of the program provided an opportunity for one study to causally identify the program's effects. The study found that the re-integration program had a profoundly positive effect on beneficiaries' livelihoods, but it had no effect on former rebels' social or political integration: former rebels were no more likely to say they were happy with the peace process, or that they preferred their peacetime lives to their lives during the war [8]. 
Another study provides a more recent randomized study of an employment project in Uganda [9]. The program provided vocational training and business start-up grants to randomly selected youth in a conflicted area in Uganda. The results are quite similar to those in the earlier study [8]. The program was very successful in increasing business assets, earnings, and work hours, but it had no effect on social cohesion and anti-social behavior.

A different study offers a further randomized control study of an employment program with an at-risk population of young men in Liberia [10]. The program offered agricultural training, capital grants, and counseling. The study collected data on a much richer set of social outcomes than the previous study mentioned above [8]. It found that the men who received the program reduced their illegal activities by $20 \%$, but that almost none of them relinquished illegal activities altogether. Furthermore, the program had no discernible impact on social networks, relationships with former commanders, aggression, or social integration. As in the previous studies ([8], [9]), this study found that the program had no impact on attitudes toward the use of violence or democracy [10].

One reason that has been proposed for the weak relationship between employment and rebellion is that workers in LIC labor markets do not typically have a job per se, but instead maintain a portfolio of work that insures them against meager work opportunities in any one of the components of the portfolio [8], [10]. Mercenary work in rebellion is another element of this portfolio for some people and one that workers see no reason to relinquish, given the vagaries of LIC labor opportunities [3], [10]. A second reason is that in civil-war-plagued societies joining a rebel group is often actually less risky than being an independent civilian, who can be susceptible to the predations of the various sides in the civil war. Thus, people may join a rebel movement to obtain security that is not available to them through legitimate employment [11].

\section{The "social cause" of rebellion}

A main argument of this article is that people join rebellions for social reasons, i.e. to contribute to a cause they think is just and to effect what they regard as positive social change. This does not of course suggest that these causes are necessarily just or that the change the rebels are trying to effect is necessarily positive, only that the adherents to these movements firmly believe in their cause. For this reason, the kinds of employment offered by the programs may not be good substitutes for membership in a rebel organization because they do not satisfy the desire to be a part of a movement that is effecting positive social change.

Most people choose voluntarily to enter into rebellion (child soldiers and abductees being exceptions), which suggests that they are a differed type of person from those who do not make the same choice. Rebels make up a relatively small portion of society and thus it seems plausible they may have different preferences than average citizens. They "self-select" into rebel activity, which of-and-by-itself, makes them different from most other citizens. Presumably, they feel more strongly about the cause for which they are fighting than do non-joiners, and for that reason may be less susceptible to economic appeals. Moreover, once people join rebel organizations they are exposed to the organization's initiation rituals and indoctrination efforts. Both of these considerations indicate that people who join rebel movements are probably innately quite different from the members of society that do not join rebel movements, and those differences are enhanced the longer these individuals participate in, and are indoctrinated by, the rebel group. 
People often join and fight for insurgent groups for a social cause-e.g. aiding the oppressed classes, achieving national ethnic autonomy, restoring the caliphate. Leaders of rebel movements work very hard to indoctrinate their recruits and strengthen these motivations. Religious extremist groups have also been described as supplying "club goods," which include social status, a sense of belonging, and a feeling of contributing to a greater good, as well as mutual material aid [12].

One study provides further evidence for this argument [13]. The authors use two "behavioral games" (i.e. activities designed to demonstrate the effects of psychological, social, cognitive, and emotional factors on economic decision-making) conducted as a laboratory experiment, to measure the "pro-sociality" of former rebels who participated in the Maoist insurgency in Nepal. Figure 1 illustrates the general relationship. Former rebels who served for a longer period of time in the movement contributed more to the "collective good" during the experiment.

Figure 1. The "pro-sociality" of former rebels who served in the Maoist insurgency in Nepal-

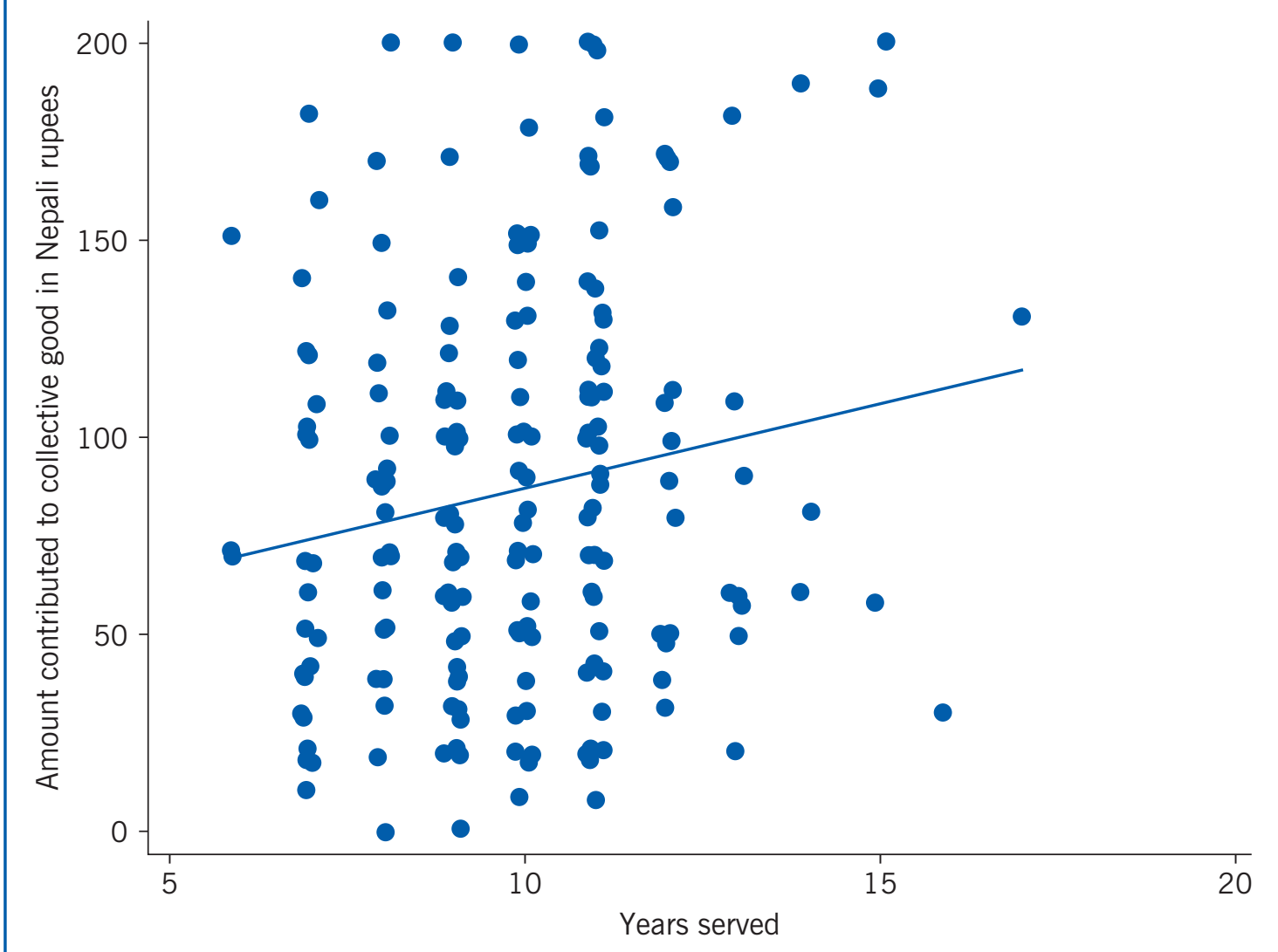

Note: "Collective good" refers to contributions to two laboratory activities that were designed so that the subjects' monetary contributions benefitted the group of participants in the experiment more than the individual contributor.

Source: Data from Gilligan, M. J., P.B. Khadka, and C.D. Samii. "Social incentives in insurgency." New York University, 2015 [13].

There are four possible explanations for this positive relationship. First, more pro-social people may have joined the movement earlier, i.e. the positive relationship between length of service and pro-sociality in the laboratory is simply due to selection effects, and the insurgents' pro-sociality within the organization did not increase over the course of their participation in it. Second, the longer they served in the movement the longer they were exposed to, and affected by, social appeals and indoctrination, thus increasing the 
pro-sociality of the members with each passing year of their participation. Third, the longer they served in the movement, the more family and friends may have joined the movement. In which case, their greater contributions to the group collective good may not have been due to more pro-social attitudes to the group as a whole but as a result of allegiance to members of their pre-existing social networks of friends and family, who became more numerous in the group. Fourth, increasingly pro-social people may have been defecting from the movement as time went by so that at the end of the war only those with the highest pro-sociality remained.

The authors find that the first two processes are operating and the third and fourth are not. More pro-social individuals entered the movement earlier (suggesting self-selection into the movement) and all rebels became more pro-social the longer they were in the movement (suggesting indoctrination by the movement). They find evidence contrary to the latter two mechanisms. There is no evidence that people contributed more because their pre-existing social networks became more prevalent in the movement over the course of the rebels' service. Furthermore, desertion rates in the movement were far too low to account for the increases in pro-sociality as a function of time of service observed during the experiment. This last explanation also requires that increasingly pro-social people were leaving the movement as war progressed. The authors find, on the contrary, that fewer innately pro-social people were joining the movement as the war progressed. The authors also present survey evidence from both combatants and non-combatants that corroborates the laboratory findings of the importance of social motivations in the insurgency.

The results suggest that rebels might be motivated by more than purely economic considerations. Put differently, participation in these activities may provide noneconomic benefits that they cannot garner from a standard job, e.g. a sense of belonging, camaraderie, and of contributing to an important and worthwhile cause. If rebels are motivated by social incentives, it would explain their unwillingness to move out of these activities and into the "formal" sector. And if they do move into formal employment, they should be unwilling to leave behind the social ties of their illegitimate activities, as all three randomized studies described above found [12], [13].

How then might we hope to lure at-risk youth and former combatants away from rebellion and violence? One study undertook a randomized control trial that suggests a promising way forward [2]. The program for at-risk youth that they studied added cognitive behavioral therapy (CBT) to the standard employment program. CBT is a type of psychological treatment that helps patients to better understand how thoughts and feelings can influence their behavior and focuses on the formation of good habits to replace unwanted behaviors. CBT helped break down their identities as rebels and criminals and develop selfdiscipline. The program was quite successful, resulting in large and sustained reductions in crime and violence. These sorts of CBT programs are now used quite frequently, and are becoming "best-practice," in the US [2]. The results of the study could be interpreted in light of the "social-motivations model" discussed above. The non-cognitive skills that the program required of its participants may have helped them sever social ties to old social networks that reinforced rebel and criminal behavior. The program may also have reduced the status that these people previously attributed to rebel and criminal group membership.

\section{LIMITATIONS AND GAPS}

One study so far points to the importance of pro-social motivations for participating in insurgencies, which have implications for jobs programs being seen as peace-building 
tools [13]. However, more studies across different types of rebel groups and countries are necessary in order to be more certain of this claim.

The mounting field-trial evidence casts doubt on the efficacy of employment programs in reducing violence, unless those programs are accompanied by serious psycho-social programming. The field trial referred to in this contribution is perhaps the only study of such a program that has been conducted in a fragile state [2]. More work is therefore needed to reinforce this study's conclusions.

In addition, all of the field trials discussed here were undertaken in states where war had ended (i.e. "post-conflict" states) [2], [3], [8], [10]. People may join rebel organizations for security, which is something that is not typically provided through formal employment. So the effects of such programs in areas of ongoing conflict are unknown.

One study established a negative correlation between unemployment and violence in the countries it studied, but the causal mechanisms were unclear [1]; questions remain as to whether employment makes counterinsurgency more difficult, whether counterinsurgency strategies reduce both violence and employment, and whether programs that increase jobs also increase violence.

\section{SUMMARY AND POLICY ADVICE}

All of the programs discussed substantially improved their beneficiaries' livelihoods, but none of the programs affected the beneficiaries' attitudes toward violence, state legitimacy, or the rule of law [2], [3], [8], [10]. The programs are not failing to bolster employment but they are failing to create better citizens, which is something they must do if the objective is to foster peace. The one exception to this is a program that seriously tried to address the psycho-social dimension of rebellion and lawlessness with cognitive behavioral therapy [2].

Policymakers should recognize that civil unrest is not only, or primarily an economic problem. It is also a psychological, social, and political problem. Policymakers must also keep in mind that people may turn to illegitimate organizations for protection when the state is unwilling or unable to provide it. Thus policies must be designed in such a way as to address issues of security as well as these other economic and social issues.

\section{Acknowledgments}

The author thanks an anonymous referee and the IZA World of Labor editors for many helpful suggestions on earlier drafts. The author also thanks Jacob Shapiro for sharing the data from [1]. Financial support from the Folke Bernadotte Academy, Sweden is gratefully acknowledged.

\section{Competing interests}

The IZA World of Labor project is committed to the IZA Guiding Principles of Research Integrity. The author declares to have observed these principles.

(c) Michael J. Gilligan 


\section{REFERENCES}

\section{Further reading}

Dube, O., and J. Vargas. "Commodity price shocks and civil conflict: Evidence from Colombia." Review of Economic Studies 80 (2013): 1384-1421.

Skarbek, D. "Governance and prison gangs.” American Political Science Review 105 (2011): 702-716.

\section{Key references}

[1] Berman, E., M. Callen, J. H. Felter, and J. N. Shapiro. "Do working men rebel? Insurgency and unemployment in Afghanistan, Iraq and the Philippines." Journal of Conflict Resolution 55 (2011): 498-528.

[2] Blattman, C., and J. C. Jamison, and M. Sheridan. Reducing Crime and Violence: Experimental Evidence on Adult Non-Cognitive Investments in Liberia. NBER Working Paper No. 21204, May 2015.

[3] Blattman, C., and L. Ralston. Generating Employment in Poor and Fragile States: Evidence from Labor Market and Entrepreneurship Programs. White paper prepared for, and funded by, the World Bank's Development Impact Evaluation, Social Protection and Labor, and Fragility, Conflict and Violence Groups, July 2015.

[4] Cramer, C. "Homo economicus goes to war: Methodological individualism, rational choice and the political economy of war." World Development 30 (2002): 1845-1864.

[5] Galula, D. Counterinsurgency Warfare: Theory and Practice. New York: Praeger, 1964.

[6] Collier P., and A. Hoeffler. "Greed and grievance in civil war." Oxford Economic Papers 56 (2004): 563-595.

[7] Benmelech, E., C. Berrebi, and E. F. Klor. "Economic condition and the conditions of suicide terrorism." Journal of Politics 74 (2012): 113-128.

[8] Gilligan, M. J., E. N. Mvukiyehe, and C. D. Samii. "Reintegrating rebels into civilian life: Quasi-experimental evidence from Burundi.” Journal of Conflict Resolution 57 (2013): 588-626.

[9] Blattman C., N. Fiala, and S. Martinez. "Generating skilled employment in developing countries: Experimental evidence from Uganda." Quarterly Journal of Economics (2014): 697-752.

[10] Blattman, C., and J. Annan. "Can employment reduce lawlessness and rebellion? A field experiment with high-risk men in a fragile state." American Political Science Review (Forthcoming).

[11] Kalyvas, S., and M. Kocher. "How 'free' is free riding in civil war? Violence, insurgency and the collective action problem." World Politics (2007): 177-216.

[12] Berman, E., and D. D. Laitin. Religion Terrorism and Public Goods: Testing the Club Model. NBER Working Paper No. 13725, 2008.

[13] Gilligan, M. J., P. B. Khadka, and C. D. Samii. Social Incentives in Insurgency. New York University, 2015.

\section{Online extras}

The full reference list for this article is available from:

http://wol.iza.org/articles/employment-and-rebellion-in-conflicted-and-fragile-states

View the evidence map for this article:

http://wol.iza.org/articles/employment-and-rebellion-in-conflicted-and-fragile-states/map 